\title{
ChE outreach
}

\section{COMPARISON OF R AND MATLAB SIMULINK in Educating High School Students with ODE Modeling Skills}

\section{JiANMING GENG}

The Shipley School • Bryn Mawr, PA 19010

Kaiyuan Chen, Nengxin Wang, Sihan Ling, and Muqi Guo

Friends Select School • Philadelphia, PA 19102

ZuYi (JACKY) HuANG

Villanova University • Villanova, PA 19085

$\mathrm{W}$ hile the US is still the most powerful country in the world, the math performance of US high school students fails to rank within the top 10 worldwide. In a study by the Organization for Economic Cooperation and Development (OECD), the mean score in Math in PISA 2015 for U.S. high school students was below the OECD average ${ }^{[1]}$ At the same time, it was mentioned by the President's Council of Advisors on Science and Technology that: "there is a need for the United States to produce approximately 1 million college graduates with STEM backgrounds over the next decade in order to retain its historical preeminence in science and technology." ${ }^{[2]}$ In order to provide the work force with competent math skills, there is a need to design new teaching programs that motivate highschool students to learn more math. Certain K-12 outreach activities have attracted national attention, such as the online module database of chemical engineering demonstrations, ${ }^{[3]}$ web-based interactive game design, ${ }^{[4]}$ the Chem-E-Car program, ${ }^{[5]}$ the Simple Experiment-Based Smartphone Education Application, ${ }^{[6]}$ and Student-Created YouTube Videos for transport phenomenon. ${ }^{[7]}$

Building on the enthusiasm for such aforementioned K-12 activities, we present a K-12 outreach approach that is specifically designed to motivate high school students to learn mathematical modeling and programming. Our previous work $^{[8-10]}$ shows that providing students with good comput- er-based tools and interesting research projects can enhance students' skills and promote their interest in math-related work. In particular, during the summer of 2014, we developed an on-site training module of the MATLAB Simulink

Zuyi (Jacky) Huang is an associate professor in the Department of Chemical Engineering at Villanova University. He is enthusiastic in applying innovative teaching methods in class to educate students with modeling and control skills. He developed flipped-classroom modules to teach undergraduates control-related MATLAB techniques in his Chemical Process Control class. He and his colleagues at Villanova received the 2016 ASEE ChED Joseph J. Martin Award for their video-based modules that introduce students to basic biological concepts and experimental skills. He is the director of the Biological \& Environmental Systems Engineering Lab (BESEL). His research is focused on developing advanced modeling and systems analysis techniques to manipulate microbial biological systems for generating biofuels from wastewater and for combating biofilm-associated pathogens. He is interested in developing STEM outreach programs for educating highschool students with modeling skills.

Jianming Geng is a senior high school student at The Shipley School, Bryn Mawr, PA.

Kaiyuan Chen is a junior high school student at Friends Select School, Philadelphia, PA.

Nengxin Wang is a junior high school student at Friends Select School, Philadelphia, PA.

Sihan Ling is a senior high school student at Friends Select School, Philadelphia, PA.

Muqi Guo is a senior high school student at Friends Select School, Philadelphia, PA. 
program for a local high-school student to solve an ODE model of microbial fuel cells (MFC). MATLAB is one of the most commonly-used programming software packages in engineering. ${ }^{[11]}$ Simulink, one of the modules of MAT$\mathrm{LAB}$, provides a friendly user-interface on which our selected high-school student was able to develop ODE models such as building with Legos. ${ }^{[12,13]}$ While Simulink provides a good platform with which high school students can build ODE models, presenting high school students with research projects can further motivate them to apply Simulink modeling skills to solving real problems. A microbial fuel cell can convert the organic compounds from waste streams into electricity. ${ }^{[14,15]}$ The student in our study was interested in this research question and in finding a sustainable approach for handling waste streams and generating electricity at the same time. Developing ODE models for such a scenario can allow students to study the mechanism of microbial fuel cells and to explore opportunities for optimizing the operation and design of fuel cells. The high school student presented his work at the 2015 ASEE-SE conference. ${ }^{[8]}$

On the basis of the feedback from the student participating in the project in 2014, we further developed our training module and made it available online so that more students could benefit. Two local high school students tested the online training modules and successfully finished the MFC modeling project during the summer of 2016. Their results were presented at the 2017 ASEE Mid-Atlantic conference. [9]

While MATLAB Simulink proved to be an effective tool for training high-school students with modeling skills, it is not free to students. This may limit the access of the training to students from low-income families. $\mathrm{R}$ language, on the other hand, is free and so can be accessed by students from low-income families and from developing countries. Similar to MATLAB, R language provides another tool used widely within the STEM fields, such as in analyses of geographical data, environmental data, ${ }^{[16]}$ image data, ${ }^{[17]}$ biometric data, ${ }^{[18]}$ medical data, ${ }^{[19]}$ statistical data, ${ }^{[20]}$ and data in traditional engineering ${ }^{[21]}$ Yet, developing models in $\mathrm{R}$ requires students to type in the codes line by line, unlike being able to connect the existing model components for building models, as Simulink allows. In this work, we mainly aim to investigate the following two objectives: 1) comparing MATLAB and $\mathrm{R}$ in teaching modeling skills to high school students; and 2) demonstrating that learning $\mathrm{R}$ may be doable but challenging to high-school students. In particular, we offered five local high-school students training in both Simulink and R and compared their performance in the MFC modeling project during the summer of 2017. While it could be helpful to test Simulink and $\mathrm{R}$ with a larger number of students so as to draw more statistically significant conclusions, our study was limited to five students because of the instructor's time for student supervision.

\section{MATERIALS AND METHODS}

\section{The Teaching Approach}

The teaching approach generally consisted of the following three modules: Simulink/ $\mathrm{R}$ training, the introduction of the MFC ODE model, and the development of the MFC ODE model. High school students were given on-site lectures two hours per week for 9 weeks according to the following schedule: the instructor (i.e., Dr. Zuyi Huang, a faculty member at Villanova University) introduced students to MATLAB Simulink, including basic MATLAB commands like the plot function and simulation of the liquid level ODE model and the enzymatic ODE model (Weeks 1 and 2); the instructor introduced the background information of microbial fuel cells and the MFC ODE model (Week 3); students built MFC ODE model in Simulink and presented the work to the instructor (Weeks 4 and 5); the instructor introduced $\mathrm{R}$ language and led students to build $\mathrm{R}$ programs for the liquid level ODE model and the enzymatic ODE model (Weeks 6 and 7); students developed their R programs for the MFC ODE model (Weeks 8 and 9); students completed anonymous surveys on evaluating the improvement in their skills in solving ODE models using MATLAB Simulink and R. Students were asked to compare their learning experience of MATLAB Simulink and R and to provide feedback on what they liked or disliked about each. The instructor provided an overview on the relevance of ODE modeling as well as MATLAB or R in STEM practice in the first lecture so that students gained a big picture of the project.

Students were required to submit the programs they developed in the training each week. They mainly worked on the project during the two-hour period in class, but they could still access MATLAB on their computers and work on the project after class. Working in class enabled the instructor to offer immediate feedback on students' programs. In particular, the instructor helped students fix errors in their programs and showed them how to identify errors in their programs. The instructor also provided students with suggestions on how to avoid those errors in their programs in the future. In addition, a homework problem was designed for each example shown in the lecture so that the instructor was able to evaluate students' learning progress. The instructor also compared the simulation results from students' programs with his own programs to evaluate students' performance of using MATLAB Simulink and R to solve ODE models.

\section{The ODE model of microbial fuel cells}

The major electrochemical processes of MFC can be generally described as shown in Figure 1: 1) anodophilic bacteria form a biofilm on the surface of the anode electrode; 2) anodophilic bacteria uptake organic compounds from the waste stream (like waste water) and produce electrons, protons, and $\left.\mathrm{CO}_{2} ; 3\right)$ intracellular mediators transfer electrons from bacteria to the anode electrode surface, and electrons 


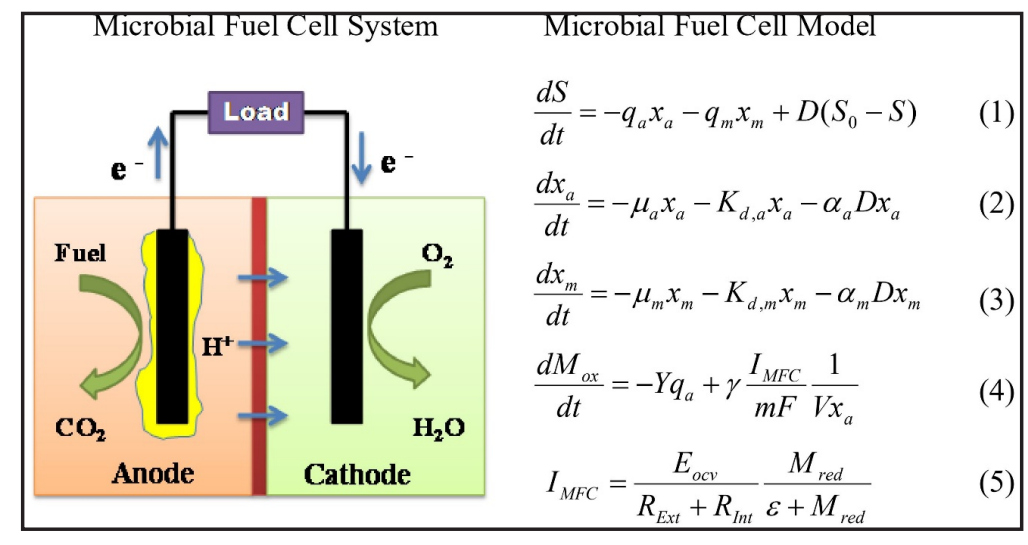

Figure 1. The diagram of electrochemical processes for a microbial fuel cell (left) and its ordinary differential equation model (right)

then translocate to the cathode electrode via an external electrical circuit; 4) the protons diffuse through the cation exchange membrane and react with $\mathrm{O}_{2}$ on the surface of the cathode electrode; and 5) the electrons are accepted by $\mathrm{O}_{2}$ to form water.

The ODE model used in the work was first presented in Reference ${ }^{[22]}$ and modified by us in $2014 .{ }^{[23]}$ The model describes the substrate concentration in the anode compartment of MFC (i.e., $\mathrm{S}$ in Eq.1), the growth of anodophilic bacteria (i.e., $\mathrm{x}_{\mathrm{a}}$ in Eq. 2), the growth of methanogenic bacteria (i.e., $x_{m}$ in Eq. 3), the intracellular mediator concentration (i.e., $\mathrm{M}_{\mathrm{ox}}$ in Eq. 4), and the electrical current (i.e., $\mathrm{I}_{\mathrm{MFC}}$ in Eq. 5). In these equations, $\mathrm{q}_{\mathrm{a}}$ and $\mathrm{q}_{\mathrm{m}}$ are the substrate consumption rates by anodophilic and methanogenic bacteria, respectively; $\mathrm{D}$ is the dilution rate; $\mathrm{S}_{0}$ is the influent substrate concentration; $\mu_{\mathrm{a}}$ and $\mu_{\mathrm{m}}$ are the growth rates of the bacteria; $\mathrm{K}_{\mathrm{d}, \mathrm{a}}$ and $\mathrm{K}_{\mathrm{d}, \mathrm{m}}$ are the decay rates of the bacteria; $\alpha_{\mathrm{a}}$ and $\alpha_{\mathrm{m}}$ are the dimensionless biofilm retention coefficients; $\mathrm{Y}$ is the mediator yield; $\gamma$ is the mediator molar mass; $\mathrm{m}$ is the number of electrons transferred per mole of mediator; $F$ is Faraday's constant; $\mathrm{V}$ is the volume of the anodic compartment; EOCV is the open circuit voltage; $\mathrm{R}_{\mathrm{Ext}}$ and $\mathrm{R}_{\mathrm{Int}}$ are the external and internal resistances, respectively; $\mathrm{M}_{\text {red }}$ is the reduced mediator fraction per anodophilic bacteria; and $\varepsilon$ is a constant. There are 25 parameters in this ODE model. Due to the space limitation, the values of these parameters along with the equations to quantify $\mathrm{q}_{\mathrm{a}}, \mathrm{q}_{\mathrm{m}}, \mu_{\mathrm{a}}$, and $\mu_{\mathrm{m}}$ are not shown here. The definitions of these parameters were cited from Reference ${ }^{[22]}$, and the values of these parameters can be found in Reference $^{[23]}$.

\section{The training module for $R$ and MATLAB Simulink}

The training module for either $\mathrm{R}$ or Simulink consists of the following four components: 1) an introduction of R or Simulink; 2) a step-by-step hands-on training in using $\mathrm{R}$ or Simulink to solve a single-equation ODE model of the liquid level in a leaking tank; 3) a step-by-step hands-on training in applying $\mathrm{R}$ or Simulink to solving a multiple-equation ODE model of an enzymatic reaction pathway involved in the human immune system; and 4) a detailed introduction of the MFC ODE model.

While the MFC ODE model has been introduced in the previous section, the ODE model of the tank liquid level is given in Figure 2. In the equation shown in Figure 2, $q_{\text {in }}$ is inlet flow-rate, $\mathrm{m}^{3} / \mathrm{min} ; K_{\mathrm{v} 1}$ is the valve coefficient, 0.000187 ; and $\mathrm{A}$ is the cross-sectional area of the tank, $0.0177 \mathrm{~m}^{2}$. The initial value of the liquid level $h$ is $0 \mathrm{~m}$. In this model, students were required to determine the liquid level $h$ at 12 minutes when $q_{\text {in }}$ begins with a value of $0.0035 \mathrm{~m}^{3} / \mathrm{min}$ and changes to $0.0050 \mathrm{~m}^{3} / \mathrm{min}$ at 6 minutes. They should plot the profile of $h$ versus time.

The enzymatic pathway consists of the reactions shown in Eqs. (6) and (7). The concentrations of enzyme $E$, substrate

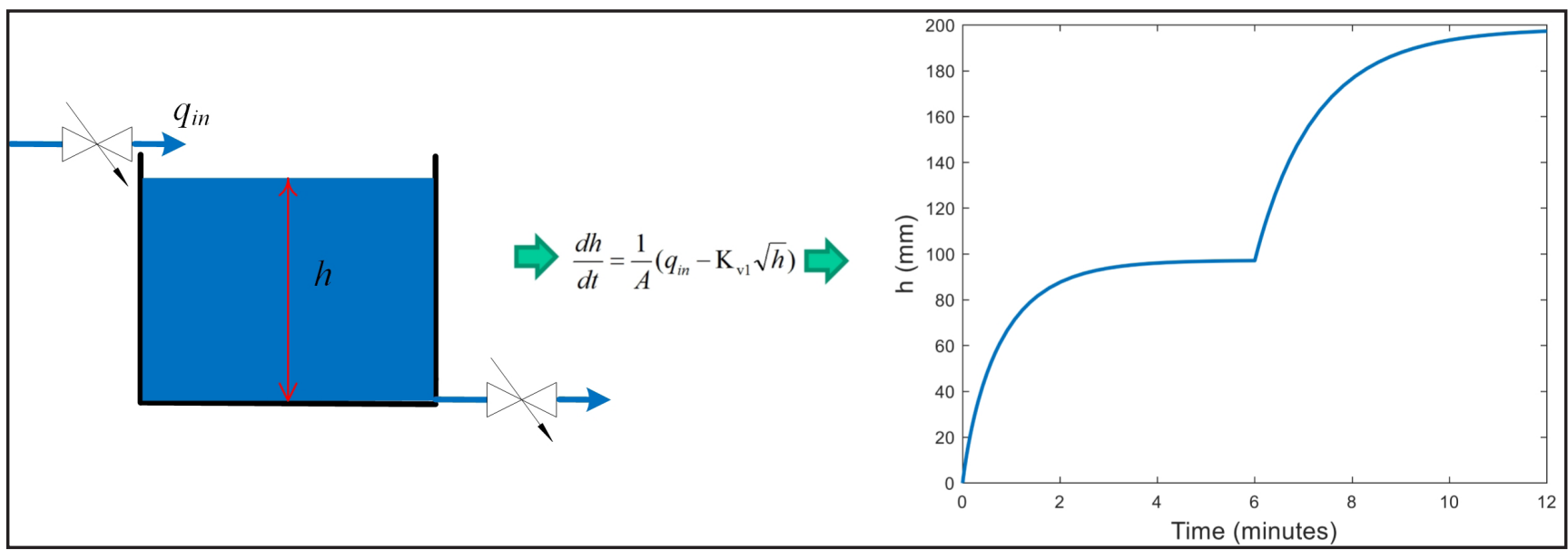

Figure 2. The model of the liquid level $h$ in the tank with water flowing out through a valve. 


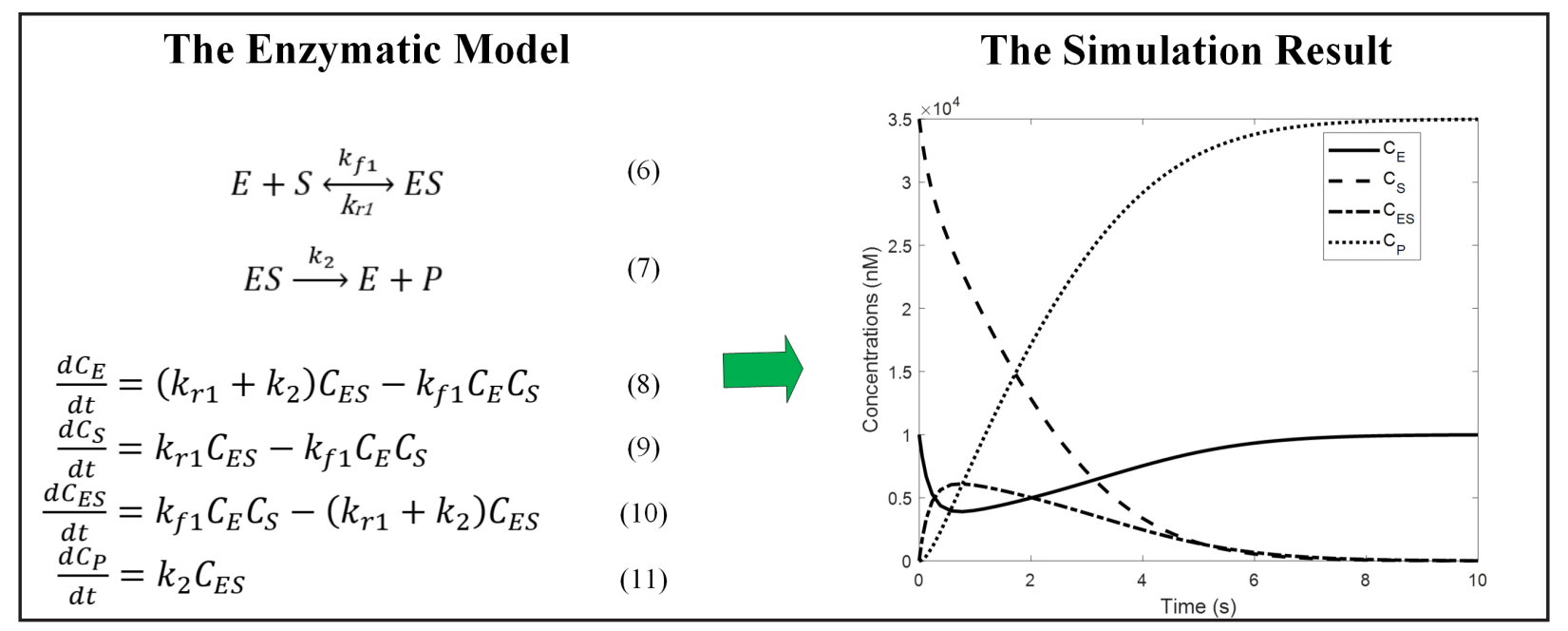

Figure 3. The enzymatic model (left) and the simulation results of the four components in the model (right).

$S$, the enzyme-substrate complex $E S$ and the product $P$ in the enzymatic reactions can be quantified by the ODE model represented by Eqs. (8-11). In these equations, $k_{f 1}$ is the forward rate constant of Reaction (6); $k_{r l}$ is the backward rate constant of Reaction (6); and $k_{2}$ is the forward rate constant of the irreversible Reaction (7). Students were required to plot the profiles of $C_{E}, C_{S}, C_{E S}$, and $C_{p 1}$ for different initial values of $C_{E}$ and $C_{S}$.

When the aforementioned ODE models were introduced to high school students, the physical meaning of each term in the ODE models was given. In addition, basic concepts of mass balance and chemical kinetics were introduced. For instance, students were taught that a larger rate constant generally means a faster reaction and that the reaction rate depends on both the reactant concentrations and rate constants. was conducted for $\mathrm{R}$ once students finished the MFC project in R. Survey 3 was designed to evaluate the improvement of students' skills to solve ODE models (Section 1), compare students' learning experience in MATLAB Simulink and R language (Section 2), and collect students' comments on open-ended questions (Section 3). The open-ended questions include: 1) what students liked and disliked about $\mathrm{R} ; 2$ ) what students liked and disliked about MATLAB Simulink, and 3) what students liked and disliked about the MFC modeling project. Sections 1 and 2 of Survey 3 are shown in Tables 2 and 3, respectively. In order to quantify students' feedback for analysis, students' responses were scaled from 1 to 5 , with 1 and 5 representing the least and strongest rating or agreement, respectively.

\section{Questionnaires to evaluate the teaching approach}

Students' performance in homework assignments and the MFC modeling project was first used as the direct evaluation for high-school students' learning in MATLAB Simulink and R. Three anonymous surveys were also used to get evaluations from students on the teaching modules. Survey 1 was used to evaluate students' experience with the designed teaching modules. Table 1 shows the questionnaire for MATLAB Simulink. The questionnaire was given to students after they developed the MFC ODE model in MATLAB Simulink. Survey 2 was similar to Survey 1 but was designed to get students' feedback on the $\mathrm{R}$ modeling module. This survey
TABLE 1

\section{Survey 1 evaluating students' learning experience in the MATLAB Simulink} training module

\begin{tabular}{|c|c|}
\hline Please think about your learning experience in the training approach & $\begin{array}{lr}\text { Totally } & \text { Totally } \\
\text { disagree } & \text { agree }\end{array}$ \\
\hline $\begin{array}{l}\text { (1) The training format is effective in conveying the MFC knowledge and } \\
\text { Simulink training }\end{array}$ & (1) (2) (3) (4) (5) \\
\hline $\begin{array}{l}\text { (2) The Simulink trainings are clear and easy to follow to reproduce the } \\
\text { simulation results }\end{array}$ & (1) (2) (3) (4) (5) \\
\hline (3) The Simulink project is too challenging to a HS student & (1) (2) (3) (4) (5) \\
\hline (4) You will recommend this Simulink project to other high-school students & (1) (2) (3) (4) (5) \\
\hline $\begin{array}{l}\text { (5) A real life-related project like microbial fuel cells makes the Simulink } \\
\text { project more attractive to you }\end{array}$ & (1) (2) (3) (4) (5) \\
\hline $\begin{array}{l}\text { (6) This project encourages you to pursue a college major in STEM field } \\
\text { (i.e., Science, Technology, Engineering and Mathematics) }\end{array}$ & (1) (2) (3) (4) (5) \\
\hline
\end{tabular}




\section{RESULTS}

The instructor of the project is a college faculty member (i.e., Zuyi Huang). Five local high school students participated in this training project in the summer of 2017. Two of them were sophomores, while the other two were freshmen. Among these five students, one of them was from The Shipley School (i.e., Jianming Geng), while the other four were from the Friends Select School. These students were selected from the instructor's connection to the aforementioned two schools in the Philadelphia area. Only one of these five students was female. Although none of these five students were from underrepresented groups in STEM, the instructor is outreaching to local high schools to make a plan for attracting underrepresented groups to this project in the future. All five students had little knowledge of ODE models, MATLAB Simulink, R programming, or microbial fuel cells. None of them had taken advanced math or biology or chemistry AP courses. The performance of these high-school students in this training project was evaluated by the instructor and then by the students themselves. The evaluation results along with feedback from the three anonymous surveys are shown and discussed as follows.

\section{Evaluation of students' improvement in $R$ and Simulink}

Simulation results from the students' programs were evaluated by the instructor. All five students were able to get correct solutions for the liquid level ODE model and the enzymatic ODE model. Two out of the five students were able to get $100 \%$ correct simulation results in both MATLAB Simulink and R. Specifically, they were able to generate the electrical current profile from the MFC ODE model (Figure statements: Simulink
TABLE 2

Section 1 of Survey 3 for evaluating the improvement of students' skill in solving ODE models

One of the major goals of the Simulink/R training is to make you more competent in solving ordinary differential equations (ODEs) of microbial fuel cells using Simulink.

(1) Rate the extent to which you are able to solve ODE models before taking Simulink/R training module

(2) Rate the extent to which you are able to solve ODE models after taking Simulink/R training module

(3) Rate the extent to the knowledge you know microbial fuel cells before doing this mini-project

(4) Rate the extent to the knowledge you know microbial fuel cells after doing this mini-project

(5) Rate the extent to which you are able to use Simulink in solving ODE models before taking Simulink training module

(6) Rate the extent to which you are able to use Simulink in solving ODE models after taking Simulink training module

(7) Rate the extent to which you are able to use R in solving ODE models before taking $\mathrm{R}$ training module

(8) Rate the extent to which you are able to use $\mathrm{R}$ in solving ODE models after taking $\mathrm{R}$ training module

TABLE 3

Section 2 of Survey 3 on comparing students' learning experience of MATLAB Simulink and R language

Please state if you agree or disagree with the following

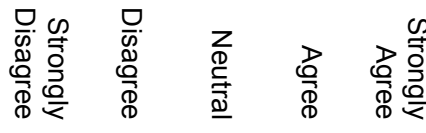

(1) You prefer R more than Simulink for solving ODE models

(2) Solving ODEs in $\mathrm{R}$ is more time-consuming than in

(3) It is easier to implement ODE models in R than Simulink

4) It is easier to debug errors/typos in Simulink than in R

(5) It is easier to learn Simulink than R

(6) You would prefer to learn Simulink first, then R

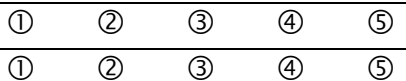

(7) It is easier to plot the profiles in R than in Simulink

\begin{tabular}{lllll|} 
(1) & (2) & (3) & (4) & (5) \\
(1) & (2) & (3) & (4) & (5) \\
(1) & (2) & (3) & (4) & (5) \\
(1) & (2) & (3) & (4) & (5) \\
(1) & (2) & (3) & (4) & (5)
\end{tabular}

4) for the scenario when the inlet flowrate was changed from 0.2 to $0.4 \mathrm{~L} /$ day in Day 1. In addition, these students predicted the electrical current produced by the microbial fuel cell for various inlet flowrates to identify the inlet flowrate that can return the maximum electrical current (Figure 5). The other three students were able to build the MFC model in both MATLAB Simulink and R, although their results were not completely correct (estimated at $60 \%$ to $80 \%$ correct). Students' performance in solving ODE models was generally similar in MATLAB Simulink and R.

While students' modeling performance in MATLAB Sim- 


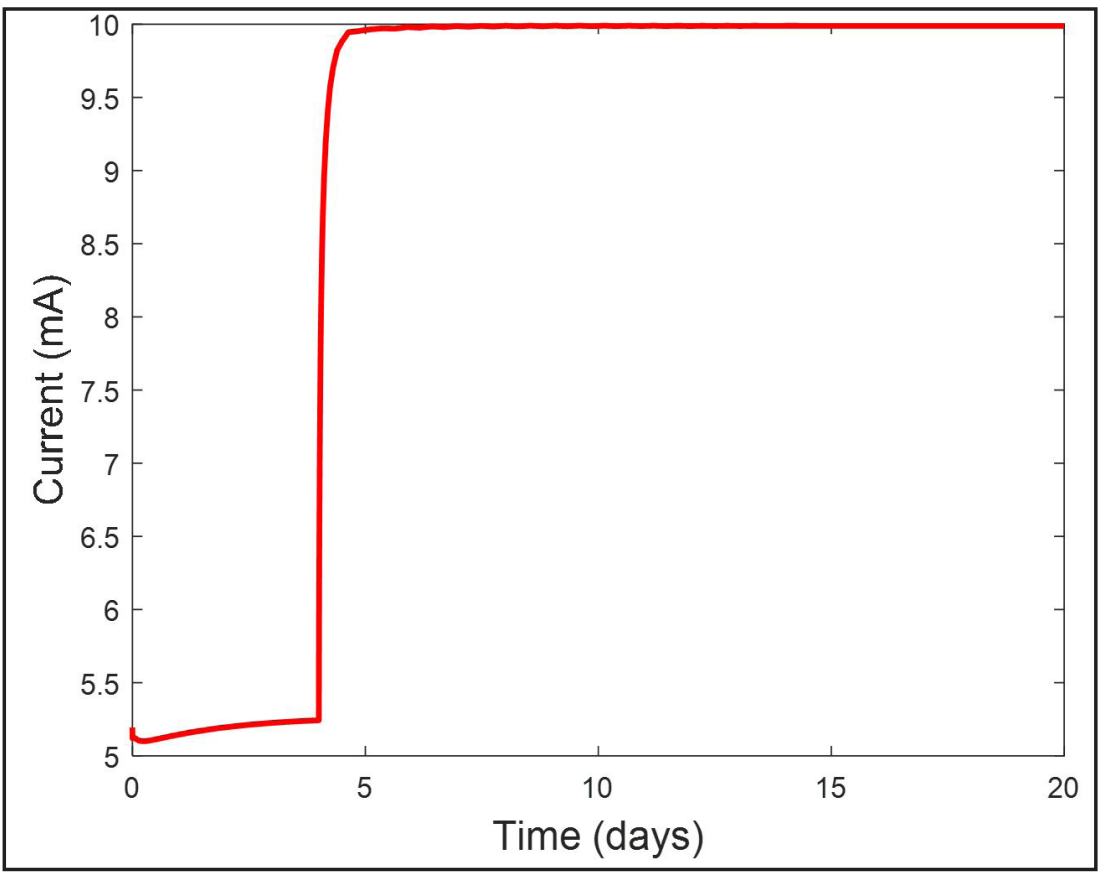

Figure 4. The electrical current for the inlet substrate concentration of $1000 \mathrm{mg} / \mathrm{L}$ when the inlet substrate flowrate is changed from 0.2 to 0.4 L/day in Day 1.

ulink and $\mathrm{R}$ was evaluated by the instructor through their work in the in-class assignments and the MFC project, Section 1 on Survey 3 was designed to obtain students' evaluation of their skills in solving ODE models using either MATLAB Simulink or R. Figure 6 shows the improvement of students' knowledge in microbial fuel cells and their skills in using MATLAB Simulink and solving ODE models. After this ODE-simulation training project, students' skill level in solving ODE models improved from 1.6 (Question 1) to 4.2 (Question 2). Students' knowledge of microbial fuel cells was enhanced from 2.0 (Question 3) to 2.75 (Question 4). Students had little experience in either MATLAB Simulink (Question 5) or R (Question 7) before the project. After the project, they rated their skills in solving ODE using Simulink (Question 6) and R (Question 8) at 4.8 and 4.2 , respectively, out of 5 . All of these conclusions were based upon the mean value of students' evaluation, as the sizes of error bars were relatively small for Questions 2, 4, 6, and 8 shown in Figure 6. While Figure 6 shows that students' skills in solving ODE using either Simulink or R were significantly improved, their knowledge of microbial fuel cells did not improve significantly (as shown in Questions 3 and 4). Potential reasons for this include: 1) none of the students took any biology or chemistry AP courses so that it was challenging for them to understand all of the terms and parameters shown in the MFC ODE model; 2) the lectures were mainly focused on introducing Simulink and $\mathrm{R}$ with not that much time to cover the background of biology and electrochemistry useful for designing MFC reactors; and 3) students didn't see and operate the real experiment system of MFC.

\section{Students' feedback on the module-based teaching approach}

Figure 7 shows students' feedback on the module-based teaching approach implemented in the project. Results of Question 1 show that the teaching approach was able to convey MFC knowledge and Simulink/R training effectively (with the score of 4 for $\mathrm{R}$ and 3.6 for Simulink). Students felt it was generally easy to follow the lectures and reproduce the simulation results in class (with the score of 4 for R and 3.2 for Simulink in Question 2). As shown in the results of Questions 3 and 4 , the project was not that challenging to high school students, and students were likely to recommend this project to their peers. The results of Question 5 indicate that real-life examples like MFC did indeed motivate students to participate in modeling-related projects. Students also felt encouraged by this project to choose STEM-related majors in their college application (Question 6). Figure 7 shows that the results of $R$ training in most questions are better than the ones of Simulink training. One potential reason is that Simulink training was given first so that

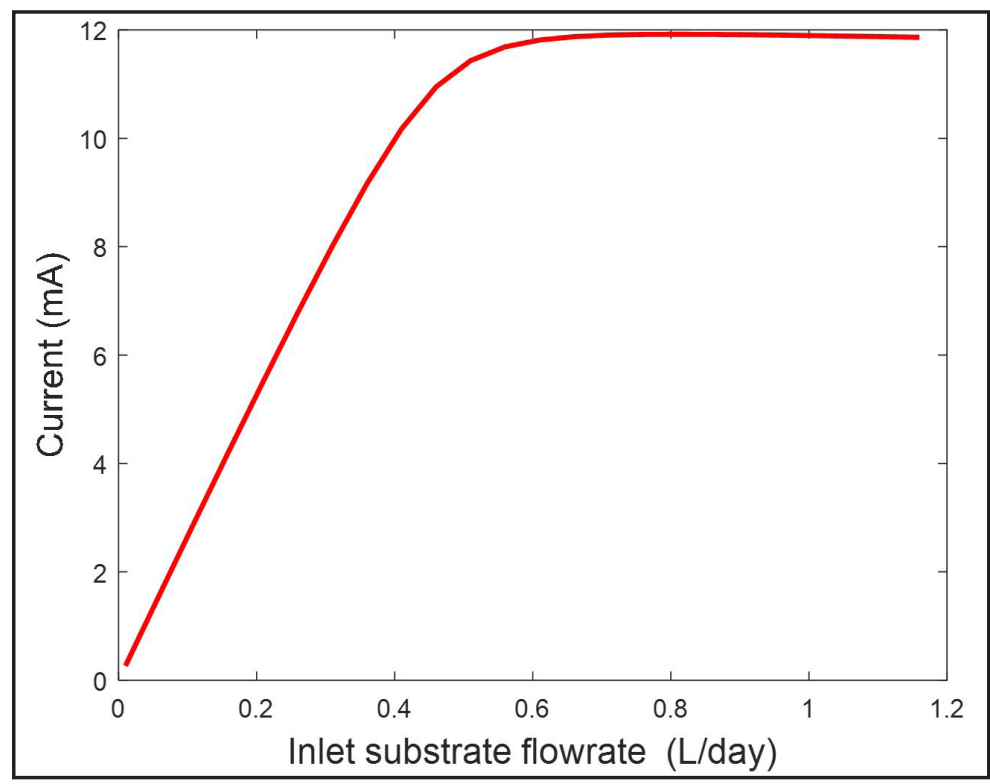

Figure 5. The steady state value of the electrical current for an inlet substrate concentration of $1000 \mathrm{mg} / \mathrm{L}$ when the inlet substrate flowrate is changed from 0 to 2 L/day gradually. 


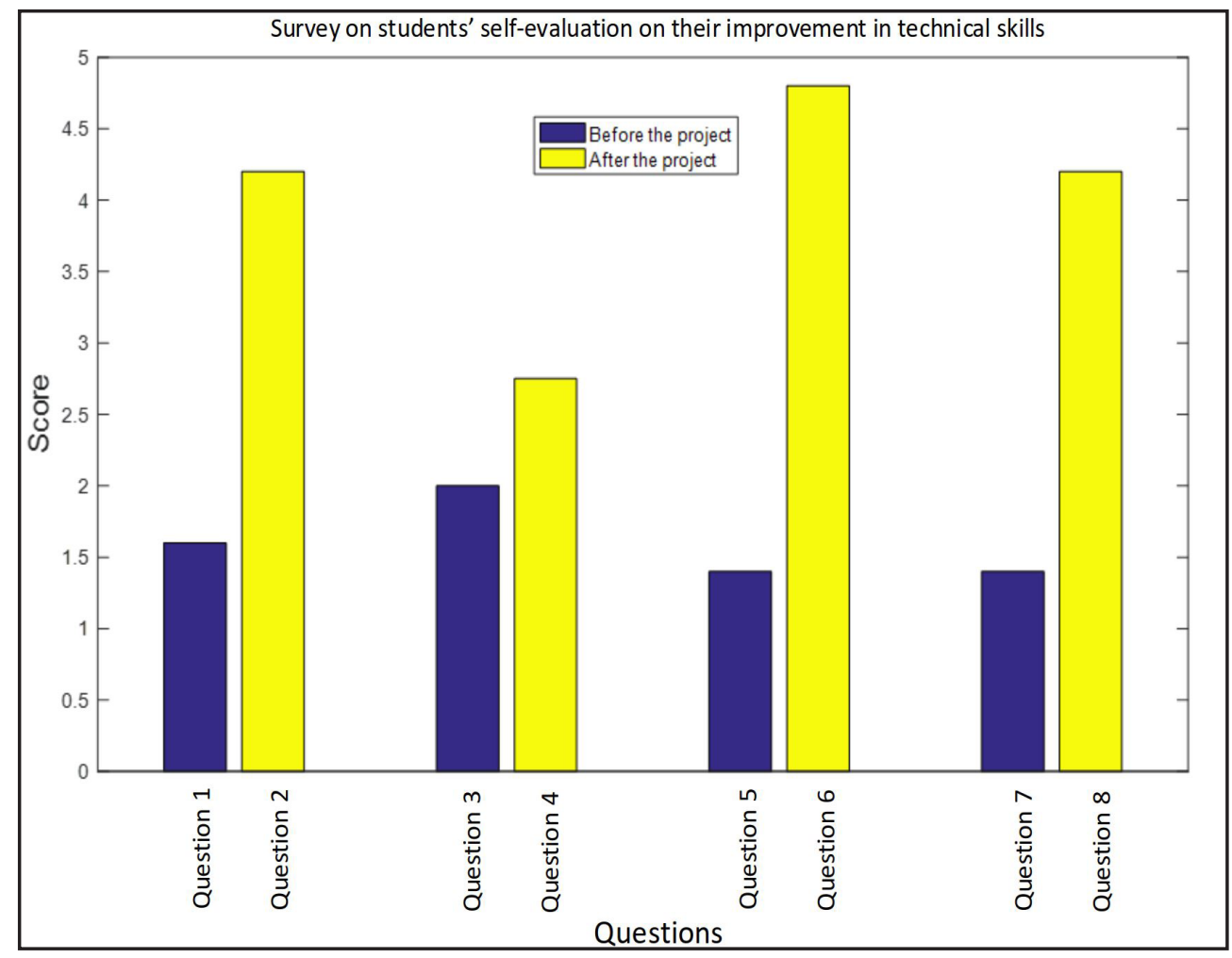

Figure 6. Survey result from students' evaluation of the improvement in ODE solving skills (Questions 1 \& 2), MFC knowledge (Questions 3 \& 4), Simulink modeling skills (Questions 5 \& 6), and R modeling skills (Questions 7 \& 8). students had obtained certain experience in modeling before they started the R-based training and simulation.

Students'feedback on $R$ versus Simulink

Figure 8 shows that students slightly preferred Simulink over R for solving ODE models (Question 1) and that they preferred to learn Simulink first and then R (Question 6), possibly due to the following reasons shown in the survey: (1) they spent more time in solving ODE models when they used R (Question 2); (2) they found it easier to input ODE models in Simulink than in R (Question 3); and (3) they preferred the function for plotting profiles in Simulink (Question 7). On the other hand, students generally felt $\mathrm{R}$ was easier to learn than Simulink (Question 5) and it was
Figure 7. Survey result from students' evaluation of: the effectiveness of the module-based teaching approach in conveying the MFC knowledge and Simulink/R training (Question 1), the clearness and easiness in implementing the lessons from the lectures to reproduce simulation results (Questions 2), the level of challenge of the project to high-school students (Questions 3), whether they would recommend this project to other high-school students (Question 4), whether a real-life example like MFC makes the project more attractive (Question 5), and whether the project encouraged students to pursue STEM majors in their college application (Question 6).

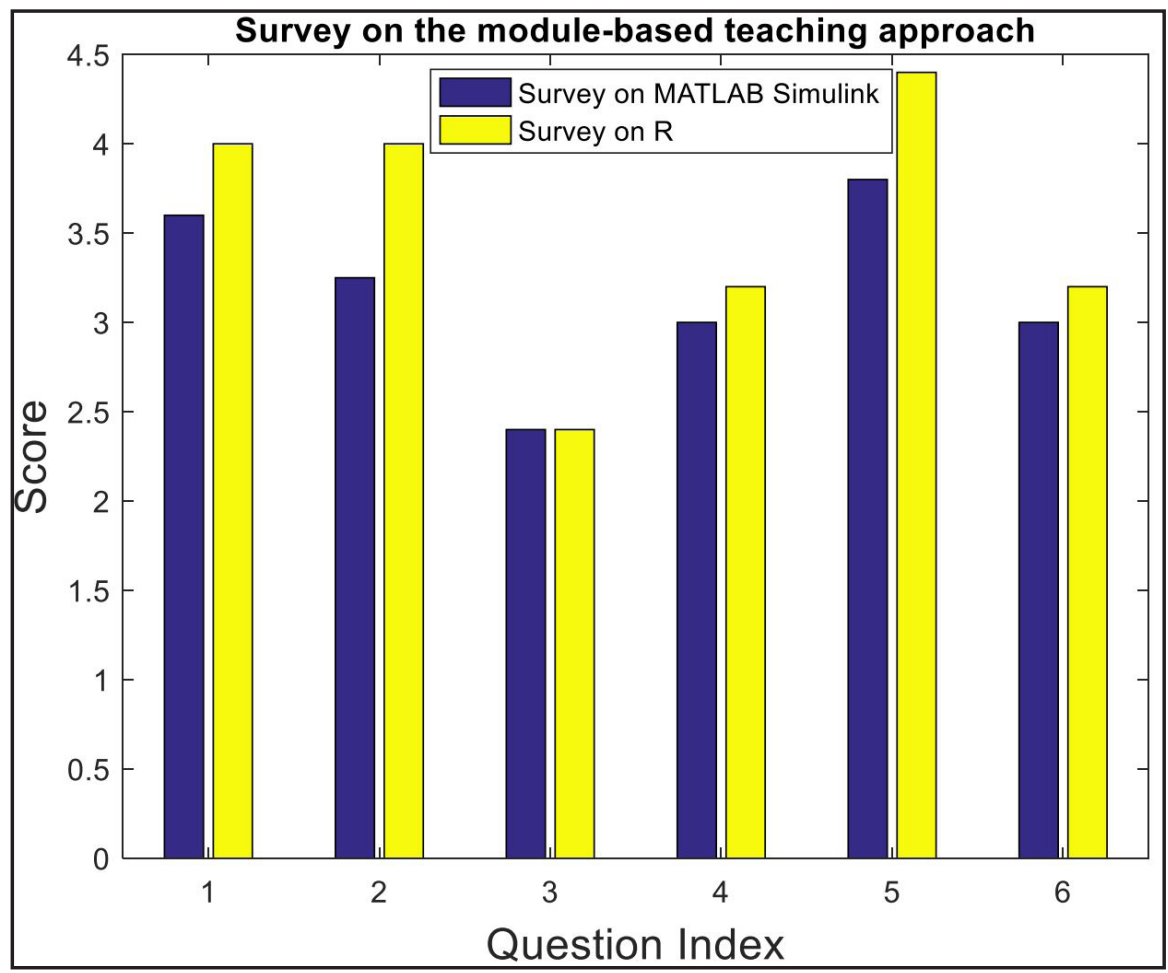


also easier to debug errors/typos in R (Question 4). Students' comments for the open-ended questions of "what they liked/ disliked about R and Simulink" are in line with the results shown in Figure 8. As for Simulink, they mentioned that: (1) Simulink helped them to visualize the ODE model and was easier to understand; and (2) they spent a large amount of time in finding errors/typos in their Simulink models. Students' comments on R include: (1) they liked being able to type ODE equations directly in $\mathrm{R}$ so that only a few lines of code were needed to represent the ODE model; (2) it was easier to make changes in ODE models in R; and (3) typing codes in $\mathrm{R}$, instead of building Lego-like modules in Simulink, made building ODE models in $\mathrm{R}$ more challenging. All students mentioned that they should be exposed to both Simulink and R.

\section{CONCLUSION AND DISCUSSION}

In this study, we designed a MFC-modeling mini-project to introduce ODE-solving skills in both $\mathrm{R}$ and MATLAB Simulink. On the basis of the instructor's direct evaluation and the students' self-evaluation on the three anonymous surveys, we conclude that: (1) students' skills in solving ODE models using either R or Simulink were significantly improved after the project; (2) students generally liked the module-based teaching approach for $\mathrm{R}$ and Simulink training; (3) students slightly preferred Simulink over R although both of them had their own advantages and constraints; (4) students liked the real-life MFC project and got motivated by this project for choosing STEM majors in their college application; and (5) students did think this project was doable for high-school students and recommended the project to their peers. While students' feedback on this project is quite positive, there is room for future investigation.

In this study, we selected R and MATLAB as they are widely used in statistical analysis and engineering, which may promote students' interest in STEM fields. In addition to $\mathrm{R}$ and MATLAB, there are other modeling software/tools that are also good for high-school students to learn. For example, Python is another widely used high-level programming language in engineering. ${ }^{[24,25]}$ It is regarded as one of the best alternatives to the commercial MATLAB. In addition, some high schools offer AP courses on $\mathrm{C}$ and $\mathrm{C}++$ to their students. ${ }^{[26]}$ These programming tools were not included in this study due to the limited time of students and also the research preference of the instructor.

The survey results from this study only represent the feedback of the five high school students participating in this project. While more student participants can provide feedback of more statistical significance, five students were selected due to the high-level student-instructor interaction needed during the training in $\mathrm{R}$ and Simulink. In particular, the instructor needed to help students with debugging their programs as some error messages were totally new to them.

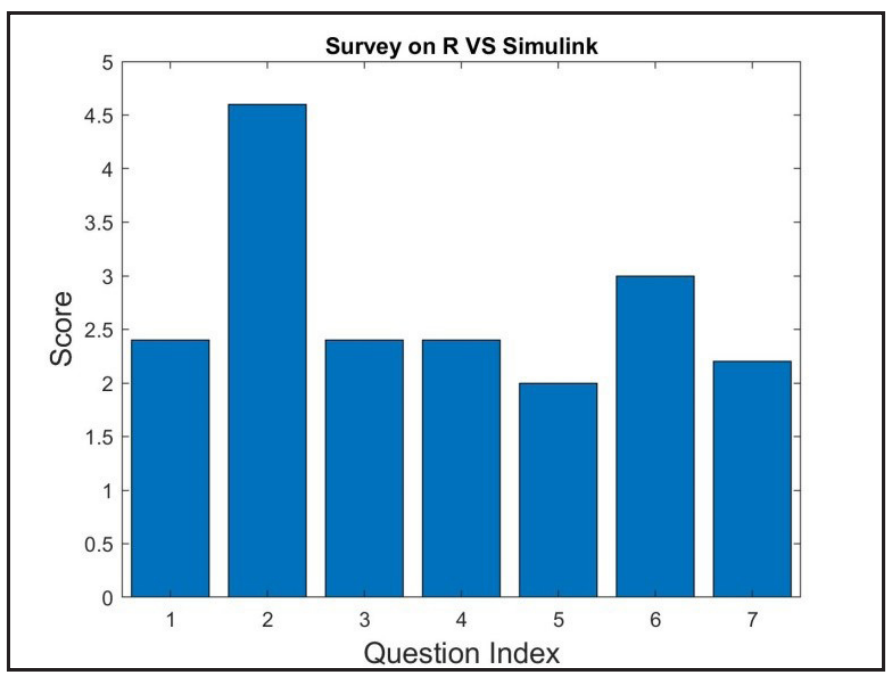

Figure 8. Survey results on the comparison of students' preference of $R$ versus Simulink: preference of $R$ over Simulink for solving ODE models (Question 1), more time-consuming in solving ODEs when students used $R$ (Question 2), easier to type ODE models in $R$ than Simulink (Question 3), easier to debug errors/typos in Simulink than in $R$ (Question 4), easier to learn Simulink than $R$ (Question 5), preference to learn Simulink first, then $R$ (Question 6), and easier to plot the profiles in $R$ than in Simulink (Question 7).

It is possible to recruit more students in this training project if teaching assistants (TAs) are available to help students check their programs. Undergraduates at the sophomore level or above after getting trained should be able to help high school students fix their programs. One potential way to increase the number of high school student participants is by implementing a video-based flipped-classroom teaching approach in which the instructor records all training videos for students to watch before they work on their own programs in class. This program can also be regarded as a service project to recruit undergraduate volunteers as TAs. The recorded videos and the undergraduate TA volunteers can significantly reduce the cost for this project and make it economically sustainable.

This project is essentially an interdisciplinary project as it involves knowledge in chemical reactions, electrical circuits, environmental engineering, mechanical properties, microbial growth, and mathematical models. It can be implemented by departments other than chemical engineering. One way to reduce the outreach investment is providing free videos in YouTube so that high school students from all over the USA can watch them. Recruiting undergraduate volunteers to answer questions from high school students will also encourage more students to participate in this project. Seminars and webinars can be given to high school teachers to encourage their students to participate in this project. It is also a good idea to work with local high schools and recruit students from different grades to identify the student groups to target. 
The students finished the Simulink training and developed the MFC ODE model in it before they were introduced to the $\mathrm{R}$ language. This may explain why students evaluated the teaching approach for $\mathrm{R}$ higher (Figure 7). Although students felt more comfortable with the teaching modules for R, they slightly preferred Simulink over R after they developed the MFC model in both platforms. Whether the training sequence of Simulink and R affects students' evaluation will be further investigated by switching the training sequence in the future.

While students provided positive feedback on this ODE-simulation training project, their evaluation of their improvement in the knowledge of microbial fuel cells was not

\section{REFERENCES}

1. https://www.oecd.org/pisa/pisa-2015-results-in-focus.pdf.

2. https://nces.ed.gov/pubs2014/2014001rev.pdf.

3. Young C and Butterfield AE (2014) Effective engineering outreach through an undergraduate mentoring team and module database. Chemical Engineering Education 48(1):31-36.

4. Orbey N, Clay M and Russell TWF (2014) Introduction to chemical engi $\neg$ neering reactor analysis: A web-based reactor design game. Chem. Eng. Educ. 28(4):199-206.

5. Chirdon W (2017) The chem-e-car as a vehicle for service learning through K-12 outreach. Chem. Eng. Educ. 51(1):11-17.

6. Stanley S and Ymele-Leki P (2017) Introducing high school students to chemical engineering kinetics with a simple experiment-based smartphone education application. Chem. Eng. Educ. 51(4):189-197.

7. Wen F and Khera E (2016) Class and home problems - Identify-solve-broadcast your own transport phenomenon: Student-created YouTube videos to foster active learning in mass and heat transfer. Chem. Eng. Educ. 50(3):186-192.

8. Ekaputra C and Huang Z (2015) Educating high school students in process simulation and control with a Simulink-based controller design for microbial fuel cells. in ASEE-SE 2015. Gainesville, FL.

9. Guo P, Yuan K and Huang Z (2017) Develop web-based modules to educate high-school students in studying microbial fuel cell dynamics. In ASEE Mid Atlantic Section Spring Conference. Morgan State University, Baltimore, Maryland.

10. Li X and Huang Z (2017) An inverted classroom approach to educate MATLAB in chemical process control. Education for Chemical Engineers, 19:1-12.

11. Berens P (2009) CircStat: A MATLAB toolbox for circular statistics. Journal of Statistical Software 31(10):1-21.

12. Parali L and Sari A (2017) Vibration modelling of piezoelectric actuator (PEA) using Simulink software, in the 4th International Conference on Electrical and Electronic Engineering (ICEEE). Ankara, Turkey.

13. Ayas MS and Altas IH (2016) A virtual laboratory for system simulation and control with undergraduate curriculum. Computer Applications in Engineering Education, 24(1): 122-130.

14. Logan BE, Hamelers B, Rozendal RA, Schrorder U, Keller J, Freguia S, Aelterman P, Verstraete W and Rabaey K (2006) Microbial fuel cells: Methodology and technology. Environmental Science \& Technology significant. One student mentioned in the open-ended questions that students needed to have preliminary background in biology and chemistry to understand the ODE model and the simulation results. Typing the MFC ODE model in either Simulink or R was not as challenging as understanding the biochemical processes that were embedded in the model. In order to address this issue, future students should be limited to those who have taken biology and chemistry AP courses. Another way to address this issue is to provide some background introduction videos to students so that they can pick up the required biology and electrochemical knowledge before the project.

40(17):5181-5192.

15. Du ZW, Li HR and Gu TY (2007) A state of the art review on microbial fuel cells: A promising technology for wastewater treatment and bioenergy. Biotechnology Advances 25(5):464-482.

16. Hanel M, Kozin R, Hermanovsky M and Roub R (2017) An R package for assessment of statistical downscaling methods for hydrological climate change impact studies. Environmental Modelling \& Software 95:22-28.

17. Bemis KD, Harry A, Eberlin LS, Ferreira C, van de Ven SM, Mallick P, Stolowitz M and Vitek O (2015) Cardinal: An R package for statistical analysis of mass spectrometry-based imaging experiments. Bioinformatics 31(14):2418-2420.

18. Bhering LL (2017) Rbio: A tool for biometric and statistical analysis using the R platform. Crop Breeding and Applied Biotechnology 17(2):187-190.

19. Cuff J and Higgins JPT (2012) Statistical analysis of surgical pathology data using the R program. Advances in Anatomic Pathology 19(3):131139.

20. Virag K (2015) A handbook of statistical analyses using R. Acta Scientiarum Mathematicarum, 81(1-2): 356-357.

21. Nadarajah S (2011) Simple R programs for statistical distributions most commonly used in engineering. Computer Applications in Engineering Education 19(4):826-834.

22. Pinto RP, Srinivasan B, Manuel MFand Tartakovsky B (2010) A two-population bio-electrochemical model of a microbial fuel cell. Bioresource Technology 101(14):5256-5265.

23. Ping QY, Zhang CY, Chen XE, Zhang B, Huang ZY and He Z (2014). Mathematical model of dynamic behavior of microbial desalination cells for simultaneous wastewater treatment and water desalination. Environmental Science \& Technology 48(21):13010-13019.

24. Millman KJ and Aivazis M (2011) Python for scientists and engineers. Computing in Science \& Engineering 13(2):9-12.

25. Perez F, Granger BE and Hunter JD (2011) Python: An ecosystem for scientific computing. Computing in Science \& Engineering 13(2):1321.

26. Astrachan O, Haynie K, Stephenson C, Diaz L and Briggs A (2010). Re-imagining the first year of computing, in 2010 ACM Special Interest Group on Computer Science Education. Milwaukee, WI. $\square$ 